Interestingly, the book is organized for individual chapter downloads directly from the publisher's website which means that citations are located after each chapter, a practice which makes searching for references easier. The end matter is similarly well constructed with a comprehensive index and a very informative appendix on how to search for patents. The only limitation in book construction is the lack of a comprehensive list of figures and diagrams, which can make searching for a specific image time consuming.

Coming in at a whopping $\$ 109.99$ for the printed book, $\$ 84.99$ for the eBook version, and $\$ 29.99$ for individual eChapters, this is by no means an inexpensive book (although, as of writing, the printed book can be purchased for just over half-price on Amazon). However, for its niche topic, and in view of the dearth of other literature on cartographic patents, it is sure to become an essential read for those interested in this area of cartographic history. As such, it is an important acquisition for map libraries, those interested in the history of cartography, and scholars in science and technology studies.

In the end, Monmonier's book provides a much-needed, in-depth, and deeply researched analysis of cartographic patents. Patents and Cartographic Inventions: A New Perspective for Map History is recommended for those interested in understanding how cartographic innovations have developed over the past century and a half.

\section{REFERENCE}

Monmonier, Mark, Adrienne L. Atterberry, Kayla Fermin, Gabrielle Marzolf, and Madeline Hamlin. 2018. A Directory of Cartographic Inventors: Clever People Awarded a US Patent for a Map-Related Device or Method. Syracuse, NY: Bar Scale Press.

\title{
OXFORD ATLAS OF THE WORLD, TWENTY-FOURTH EDITION
}

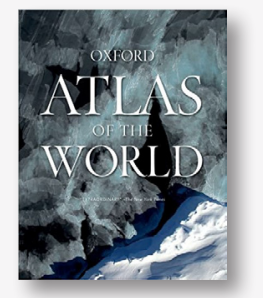

Oxford University Press USA, 2017

448 pages, $\$ 89.95$, hardcover.

ISBN: 978-0-19-084362-5

\section{Review by: Tanya Buckingham, University of} Wisconsin-Madison

The blurb on the back cover of the Oxford Atlas of the World boasts that it is "the only world atlas to be updated annually," which, incidentally, means that this review of the twenty-fourth edition, copyright 2017, should appear just barely before the twenty-fifth is released. The review begins with an inventory of the twenty-fourth edition, and is followed by a comparison with the 2016 (twenty-third) and 2014 (twenty-first) editions. A comparison to last year's offering was an obvious choice, and a look back at the twenty-first was added for two reasons: first as a point of reference as to how much the atlas has changed, and second because that edition had also been reviewed for Cartographic Perspectives (Denil 2016).

The physical copy of the atlas provided for this review is a solid, hard cover book containing 448 thick, glossy, pages. It weighs 7.4 pounds, measures 14.6 inches $\times 11.4$ inches and is 1.4 inches thick. This edition of the Oxford Atlas of the World was published on November 1, 2017.

Opening the front cover, the reader is greeted with a world map on the endpapers. The cool color scheme of greens, blues, and greys in the twenty-fourth edition is quite different from the corresponding maps in the twenty-first and twenty-third editions, which sported a wider range of hues. The colors employed to indicate the extent, scale, and page number of each of the various atlas maps remain in the same groups, but are now tertiary, rather than primary, colors. One would expect that their brightness, in contrast to the new, more subdued background, would make them stand out better than they did in the previous edition, where they had more visual competition. I don't find this to be the case, myself, but perhaps the change was made to accommodate users with color vision impairments (a condition I lack). The legends to the world, city, and physical maps are all found on the opening endpaper as well.

The atlas maintains a consistent format across its recent editions, opening with a two-page "Foreword" spread, then a "User Guide," followed by the "Table of Contents." "World Statistics" comes after that introductory material, and provides an alphabetical listing of countries along with 
data on their area, population, national capital, and annual income in US dollars. Ranking each country in each data category would make comparisons easier and enhance the utility of the list. The same is true of the "World Statistics for Cities" found on page 7.

The opening subject for the thematic content section, which follows the listing of countries and cities, differs from the earlier editions. Recent editions opened with "The Future of the Oceans and Seas," followed by a pair of twopage spreads of issues and facts facing the world's water. In the current edition, the section "A Divided World: Land and Maritime Boundaries" begins with a timely photo of a rusty border wall crawling over an arid landscape, with a cactus situated near the center of the image. The text explains: "In areas where conflict is in the past and people on both sides of the fence can benefit from the free flow of goods and people, a boundary marker may be no more than a ceremonial sign. In more contentious areas, where it is seen necessary to control movement, formidable and physical barriers may be erected. The fence shown in this image marks the division between the United States and Mexico" (9). The four pages that follow are full of maps depicting boundaries cutting through land and water. This opening section feels like a challenge to the many countries currently taking action to become more insular, and makes an interesting start to an atlas that, at its core, relies on just these sorts of boundaries to frame and classify its contents. Arguably, one purpose of an atlas is to explore geographic relationships and the context of phenomena, yet this section leaves the reader to wonder what the world might be like if "artificial constructions" like national boundaries-so sharply portrayed in the atlas-were not so definite. Certainly, the boundaries that are depicted uniformly on the atlas' maps might actually exist in many different forms on the ground. These range from "very 'closed' boundaries, such as North Korea" which restrict the movement of both people and goods, to the more fluid boundaries of the European Union, and we can see that while some states have an adversarial view of their neighbors, other "countries are willing to surrender a degree of individual sovereignty in exchange for greater collective economic or military power." This is one of many times in the course of reviewing this book that I wondered how other people consume an atlas. I know that I rarely read the front matter, and if I had not read it for this review, I would not likely have considered viewing the atlas through this lens.
The next section, "Images of Earth," displays seventeen cities around the globe. Not only is the raw, majestic beauty of the Earth's physical landscape revealed in the images, but so too is the way human existence flows around those features. The images seem to convey an empathy with the human experience that reference maps of these same places are not able, and not typically intended, to display. Adding a scale reference to these images could help the reader grasp the extent of the built human landscape, which ranges from the iconic shapes sketched by the streets of Paris to the artificial palm and world-shaped islands rising from the sea off the coast of Dubai. From the barely perceptible human habitations of Kochi, in south India-where it is the natural features that stand out and the human settlements look almost like static - to the teeming life of the twin national capitals Brazzaville and Kinshasa facing each other across the Congo River, to the linear fields of Bangkok: these images help us see both the different ways that the land impacts human life, and the similarities in patterns of human habitation arising from our dependence on the natural world.

The "Gazetteer of Nations," which follows, is a concise profile of each country's geography, climate, history, politics, and economy, and has ready-reference tables illustrated with flags and location maps. It provides about as much information as one would expect, with variables that seem to make logical sense in summing up each country, as disparate as they may be.

The "World Geography" section is, in my opinion, the best part of any atlas, and this one hosts forty-two pages on a variety of thematic topics, supported by maps, charts, graphs, and diagrams. They are heavy on text and generally follow a three-column layout, with margin vignettes. While the Oxford Atlas of the World attempts to teach through text and small graphics, in the end this section comes across as less engaging than is necessary to succeed. My preference is for an atlas that is visually captivatingone that draws the reader in, and inspires deeper learning. Much like a classroom lecturer, an atlas no longer needs to convey all of the available information to the pupil. There is room for this atlas to become more visually striking in a way that would encourage the reader to ask questions that require additional research and inquiry.

"World Geography" opens with a spread entitled "The Universe." The presentation of this material incorrectly situates our known human existence at the center of 
the universe, arguably failing one of the purposes of an atlas: to place the reader within the context of where. Cartographers have a responsibility to consider the impact of their representations, and, without additional knowledge, one could gather from the information presented here that our solar system is actually at the center of everything.

The "World Geography" segments then move through "The Solar System," "Seasons, Time and Motion," "Geology of the Earth," "The Atmosphere," "Climate," "Climate and Global Warming," "Water and Vegetation," "Oceans and Seas," "Biodiversity and the Natural World," "Population," "Cities," "The Human Family," "Conflict and Co-operation," "Energy," "Minerals," "Employment and Industry," "Trade," "Health," "Wealth," and "Standards of Living"; all are, for the most part, full of standard explanations that can be found in introductory texts on the subject. There are some striking oddities in the treatment of graphics, such as inconsistencies in how bar and pie charts are shown: some are in three dimensions, others in two; some have drop shadows, others do not. Similarly, the various maps in the "Conflict and Cooperation" spread display inconsistent coastlines, and three of them sport coastlines much too heavy and dark for their detail. The complicated graphic of air circulation on page 76 is cluttered by a topographic image, which is not only irrelevant but also out of character with the style of the other thematic maps.

Several of the maps struggle with colors that are hard to differentiate, particularly when the authors use a single hue sequential scheme; adding a second hue, or increasing the differences between class colors would help. Furthermore, there are some maps here that would cause some persons with color vision impairments a real struggle to interpret.

There are a few curious projection decisions. Just as Denil (2016) critiqued in his review of the twenty-first edition, pseudocylindrical projections are still portrayed as rectangular, where the curved edges of the water are replaced with straight edges that meet at $90^{\circ}$ angles, and indicate only the Prime Meridian and Equator. We might also ask why the Peirce projection was chosen for the "Tourism and Travel" map on the "Employment and Industry" spread, given that it emphasizes the area with the least data by placing it in the center.
The particular themes of the section differ slightly from recent editions of the atlas. "Oceans and Seas" was added in the twenty-fourth edition, pulling content from "The Future of the Oceans and Seas," which was the opening section of the previous editions. The oceanic conveyor belts map would be slightly more visually effective if the projection were centered at a location where the belts were not interrupted. To make room for this new spread, the old "Food Supply" spread is no longer part of the atlas.

As one would reasonably expect, there are modest changes to the data on these maps when compared to the earlier versions considered here. Some photos were also updated, as are some minor data categories; for instance, "Renewables" was added to the "Energy Consumption" graph in the twenty-fourth edition, and the map of inflation on the "Wealth" spread acquired "Negative Inflation" as a category. This "World Geography" theme also contains the biggest change within an existing spread. The bottom half of the second page in the previous editions had focused on Goal 1 of the United Nations Sustainable Development Goals, with a map showing "Growth in GNI" and a chart supporting some text for "Tackling Poverty - Millennium Development Goal 1.” These are no longer present, and in their place are icons representing each of the seventeen UN Development Goals. The icons are large and heavy, without much content, and what information they do convey could have been communicated more efficiently.

Following the thematic spreads are maps of seventy urban areas around the world, described as "useful for planning trips around the world, and comparative studies." The city maps include an overview of the city extent with a locator map, and some of them include a closer look at the "central" part of each city. There are varying color bars for the titles, but it is not clear what the color bars are supposed to indicate. A better use of color would have been to link the different maps of same cities together.

The bulk of the atlas, 179 pages of general physical \& political reference maps, displays Philip's (philips-maps.co.uk) cartography with relief shading and stepped hypsometric tints, starting with two world maps on a Winkel Tripel projection, centered just east of the Prime Meridian. The colors of the physical map could have been improved by using shades of the underlying hypsometric tints to represent the hillshade shadows rather than the black overprint, which muddies the color. Also, the weights of the 
elevation color steps are not even-the yellow and orange are quite close, as are the two greens.

After making stops at the Poles, the Atlantic Ocean, Greenland, and Iceland, we dive into the continents. The coverage starts with Europe and follows a zig-zag pattern: first to Asia, then Africa, to Australia, through the Pacific Ocean, over to North America, and ending in South America. One criticism here is that the North America map shows the United States and Canada with states/ provinces delineated, whereas there are no other continental maps showing equivalent sub-national administrative boundaries. Even Mexico, which appears on the same North America map, does not have its states included.

The "Geographical Glossary" fills over one hundred pages, and contains an 86,000-name index, giving latitude, longitude, and grid references for geographic features, towns, and cities. Geographic indices like this obviously play a large role in the utility of the atlas, are no small task to create. At the close of the book, the endpapers show a guide to the European maps, in the same style as the reference map of the world with which the atlas opened.
The cover of the Oxford Atlas of the World proudly displays praise from a number of reputable sources, including The New York Times, which remarked: "Extraordinary." The same supportive comments appear on each of the three editions at which I looked, making me wonder how long ago it earned the praise, though for the most part the changes to the atlas through editions twenty-one, twenty-three, and twenty-four are modest data updates. If you are simply wondering whether to update your copy with the latest edition, you may want to consider how much time has passed since your last purchase, and how much the data may have changed. If, on the other hand, you are looking to add a world atlas to your collection, the compact size and introductory coverage of topics in the twenty-fourth edition of the Oxford Atlas of the World make it useful for a number of general purposes. This atlas is neither flashy nor dramatic, but it is a sturdy and reliable product that seems to convey a good range of information in straightforward manner.

\section{REFERENCE}

Denil, Mark. 2016. "Review of Oxford Atlas of the World, Twenty-First Edition.” Cartographic Perspectives 83: 35-39. doi: 10.14714/CP83.1349. 